Jaume Roquer

Ana Rodríguez-Campello

Meritxell Gomis

Angle Ois

José Enrique Martínez-Rodríguez

Elvira Munteis

Jordi Jiménez Conde

Joan Montaner

José Álvarez Sabín
Received: 31 October 2005

Received in revised form: 23 January 2006

Accepted: 24 January 2006

Published online: 28 August 2006
J. Roquer ( $₫)$

A. Rodríguez-Campello, MD

M. Gomis, MD - A. Ois, MD

J.E. Martínez-Rodríguez, MD

E. Munteis, MD · J. Jiménez Conde, MD

Servei de Neurologia

Hospital del Mar

Passeig Maritim 25-29

08003 Barcelona, Spain

Tel.: +34-93/2483236

Fax: +34-93/2483235

E-Mail: 35826@imas.imim.es

J. Montaner, $\mathrm{MD}, \mathrm{PhD}$

J. Álvarez Sabín, MD, PhD

Unitat Neurovascular

Servei de Neurologia

Hospital Universitari de la Vall d'Hebró

Barcelona, Spain

\title{
Comparison of the impact of atrial fibrillation on the risk of early death after stroke in women versus men
}

Abstract Background Atrial fibrillation (AF) is considered a predictive factor of poor clinical outcome in patients with an ischemic stroke (IS). This study addressed whether the impact of AF on the in-hospital mortality after first ever IS is different according to the patient's gender. Methods We prospectively studied 1678 patients with first ever IS consecutively admitted to two University Hospitals. We recorded demographic data, vascular risk factors, and the stroke severity (NIHSS) at admission analyzing their impact on the in-hospital mortality and on the combined mortality-dependency at discharge using a Cox proportional hazards model. Two variable interactions between those factors independently related to in-hospital mortality and combined mortality-dependency at discharge were tested. Results Overall inhospital mortality was $11.3 \%$. Cox proportional hazards model showed that NIHSS at admission (HR: 1.178 [95\% CI 1.149-1.207]), age (HR: 1.044 [95\% CI 1.0261.061]), AF (HR: 1.416 [95\% CI
1.048-1.913]), male gender (HR: 1.853 [95\% CI 1.323-2.192) and ischemic heart disease (HR: 1.527 [95\% CI 1.063-2.192]) were independent predictors of in-hospital mortality. A significant interaction between gender and AF was found $(p=0.017)$. Data were stratified by gender, showing that AF was an independent predictor of poor outcome just for woman (HR: 2.183 [95\% CI 1.403-3.396]; $p<0.001$ ). The independent predictors of combined mortality-disability at discharge were NIHSS at admission (HR: 1.052 [95\% CI 1.041-1.063]), age (HR: 1.011 [95\% CI 1.0041.018]), AF (HR: 1.197 [95\% CI 1.031-1.390]), ischemic heart disease (HR: 1.222 [95\% CI 1.0041.488]), and smoking (HR: 1.262 [95\% CI 1.033-1.541]).

Conclusions The impact of AF is different in the two genders and appears as a specific ischemic stroke predictor of in-hospital mortality just for women.

Key words: ischemic stroke atrial fibrillation - gender differences - outcome

\section{Introduction}

Age $[3,9,18,22,24,31,32,35,36]$, atrial fibrillation zo $[8,18,21,22,26,33,38](\mathrm{AF})$ and stroke severity
$[1,8,18,22,32,35,36]$ are the most powerful predictors of in-hospital death for patients with ischemic stroke (IS). Other factors such as female gender [4], diabetes [3, 9, 18, 22, 24, 26, 31, 32, 33, 35, 36, 
38], hyperglycemia [29, 37], congestive heart failure $[24,29]$, previous stroke [18], previous ex-smoker status [38], body temperature [27, 36], high and low admission blood pressure-values [7, 34], elevated pulse pressure [5], and early impairment in consciousness [10] have also been reported. In recent years, there has been an increasing interest in analyzing stroke characteristics and clinical outcome in different subgroups of patients such as women $[4,28]$ and older patients [3, 22]. Nevertheless, specific data on early mortality predictors in these populations are scarce. In this way, some studies have suggested that factors influencing early death after acute stroke are different in older patients from those in younger ones as well as in men versus women [18], and that the impact of AF could differ in the two genders. Information about these interrelations and their final real impact on outcome would be of interest in estimating more accurately those factors influencing early mortality after acute IS. The aim of our study was to assess if in-hospital mortality and functional dependence at hospital discharge differ between male and female patients with IS and AF.

\section{Methods}

We analyzed 1860 consecutive patients with first ever acute IS admitted to two University Hospitals. IS diagnosis was performed following the World Health Organization definition of stroke [2]. All patients were assessed within 24 hours of stroke. Cases with a diagnosis of transient ischemic attack, subarachnoid hemorrhage, subdural or extradural hemorrhage, brain injury resulting from trauma or neoplastic causes, or those with a previous clinical stroke were excluded. From the total of 1860 patients registered, 97 were excluded from further analyses because of incomplete data, 85 additional patients were not included in the analysis because they were treated with tPA $(n=51)$ or were included in neuroprotective pharmacological trials $(n=34)$. Finally, 1678 patients were studied. Data were obtained for patients, via their next of kin, or from medical records. All patients fulfilled a clinical protocol which included demographic data, previous antiplatelet or anticoagulant treatment, vascular risk factors (arterial hypertension, diabetes, AF, previous ischemic heart disease, and current smoking), the stroke severity measured by the National Institutes of Health Stroke Score (NIHSS) [16, 17] at admission, and the combined mortalitydependency status at discharge using the modified Rankin Scale (mRS). The diagnosis of cerebral infarction was confirmed in all patients by brain computed tomography or magnetic resonance imaging. We considered AF when it was documented by two EKGs or when it was detected during hospitalization. The primary outcome of the study was early death, defined as in-hospital mortality.

\section{Statistical analysis}

We analyzed the impact of age, gender, previous antiplatelet or anticoagulant treatment, arterial hypertension, diabetes, AF, ischemic heart disease, current smoking and NIHSS on in-hospital mortality. Qualitative variables were recorded as percentages and quantitative variables as mean and standard deviations. The t-test was used to test differences in continuous variables and the Chi square test for those in proportions. The Cox proportional hazards model was performed to estimate hazard ratios (HR) and the resulting $95 \%$ CI of predictors of in-hospital mortality. Length of acute care hospital admission was defined as survival time. Inhospital death was defined as outcome event. Patients were censored if they were alive at discharge. In the first step, we performed a univariate analysis to determine which variables were related to an increase of in-hospital mortality. Then, by means of the Cox proportional hazards model, we analyzed the independent predictors of in-hospital mortality after controlling for possible confounding variables according to the results of the univariate analysis (variables that reached a $\mathrm{p}<0.15$ were included in the regression model). To evaluate gender differences in the prediction of in-hospital mortality, gender was included in the model. Gender, previous antithrombotic treatment, arterial hypertension, diabetes, $\mathrm{AF}$, ischemic heart diseases and current smoking were included as qualitative variables. Age and NIHSS values were included as quantitative variables. Using the same methodology, we also analyzed the predictors of combined mortality-dependency at discharge after dichotomizing the series into two groups: non-disabled patient ( $\mathrm{mRS}$ from 0 to 2 ) and death-disabled patients ( $\mathrm{mRS}$ from 3 to 6). Possible two variable interactions between those factors independently related to in-hospital mortality and for combined mortality-dependency were also evaluated. All tests were 2-tailed, and significance was determined at a $\alpha$ level of 0.05 . Statistical analyses were performed with the SPSS 11.5 software package.

\section{Ethics}

The information of the study was collected from the prospective clinical protocols of both participants' hospitals, which fulfilled the local ethical guidelines. The identity of the individual patients was completely anonymous. Therefore, no specific informed consent was signed by patients.

\section{Results}

Demographic and baseline data of the patients and the results of the univariate analysis of factors related to in-hospital mortality are summarized in Table 1. Median length of hospitalization was $11(7,16)$ days. Overall in-hospital mortality was $11.3 \%(10.9 \%$ in men and $11.6 \%$ in women). When mortality was analysed by age subgroups ( $<$ or $\geq 75$ years), it was lower in women for both age groups $(4.9 \%$ in $<75$ years; $16.1 \%$ in $\geq 75$ years) compared with men $(5.7 \%$ in $<75$ years and $19.9 \%$ in $\geq 75$ years, $p=n s)$. Kaplan Meier test showed that mortality at 30-day was $21.3 \%$ (95\% CI: 17.3-25.4).

Predictors of in-hospital mortality by Cox proportional hazards model are showed in Table 2. Current smoking (HR: 1.059, [95\% CI: 0.700-1.604], $\mathrm{p}=0.785$ ), and previous antiplatelet treatment (HR: 1.089, [95\% CI: 0.769-1.543], $\mathrm{p}=0.631$ ) did not reach statistical significance. The two variable interactions between independent predictors of in-hospital mortality showed no significant interaction between age and AF ( $\mathrm{p}=0.789)$, ischemic heart disease and gender $(p=0.917)$, age and gender $(p=0.789)$, and age 
Table 1 Univariate analysis of patients according to in-hospital mortality after first ever ischemic stroke

\begin{tabular}{|c|c|c|c|c|}
\hline & $\begin{array}{l}\text { Total cases } \\
(\mathrm{n}=1678)\end{array}$ & $\begin{array}{l}\text { In-hospital death } \\
(\mathrm{n}=189)\end{array}$ & $\begin{array}{l}\text { Survival at discharge } \\
(\mathrm{n}=1489)\end{array}$ & $\begin{array}{l}p \text { value } \\
\text { [OR }(95 \% \mathrm{Cl})]\end{array}$ \\
\hline Mean age (SD), years & $72.8(12.3)$ & $80.6(9.1)$ & $71.8(12.3)$ & $0.0001(*)$ \\
\hline Men $(\%)$ & $852(50.8)$ & $93(10.9)$ & $759(89.1)$ & \\
\hline Women (\%) & $826(49.8)$ & 96 (11.6) & $730(88.4)$ & $0.647[0.93(0.68-1.28)]$ \\
\hline Arterial hypertension (\%) & $1022(60.9)$ & $116(61.3)$ & $906(60.8)$ & $0.860[1.02(0.74-1.41)]$ \\
\hline Diabetes mellitus (\%) & $500(29.8)$ & $61(32.3)$ & $439(29.5)$ & $0.433[1.14(0.81-1.60)]$ \\
\hline Ischemic heart disease (\%) & $247(14.7)$ & $41(21.7)$ & $206(13.8)$ & $0.004\left(^{*}\right)[1.73(1.16-2.55)]$ \\
\hline Atrial fibrillation (\%) & $523(31.2)$ & $105(55.6)$ & $418(28.1)$ & $0.0001\left(^{*}\right)[3.20(2.33-4.41)]$ \\
\hline Current smoking (\%) & $467(27.8)$ & $40(21.2)$ & $427(28.7)$ & $\left.0.030{ }^{*}\right)[0.69(0.46-0.96)]$ \\
\hline Previous antiplatelet treatment (\%) & $335(19.9)$ & $49(25.9)$ & $286(19.2)$ & $\left.0.030{ }^{*}\right)[1.47(1.02-2.12)]$ \\
\hline Previous anticoagulant treatment (\%) & $77(5.9)$ & $12(4.2)$ & $65(6.1)$ & $0.22[0.67(0.36-1.27)]$ \\
\hline NIHSS at admission, (median, q1-q3) & $7(3,16)$ & $20(17.5,21)$ & $3(6,12)$ & $0.0001(*)$ \\
\hline
\end{tabular}

Mean values; SD values in parentheses.

Median values, Quartile 1-3: quartile values in parentheses.

$(*)$ Variables included in the Cox proportional hazards model.

and NIHSS $(\mathrm{p}=0.731)$. However, a significant interaction between gender and AF was found ( $p=0.017$ ). Therefore, data were stratified by gender. The results of the Cox proportional hazards model is shown in Table 3. Previous antiplatelet treatment (HR 0.934, [95\% CI: $0.568-1.536], \mathrm{p}=0.788$, for women; HR: 1.164, [95\% CI: $0.703-1.929], \mathrm{p}=0.555$ for men); ischemic heart disease (HR 1.457, [95\% CI: 0.8672.450], $\mathrm{p}=0.156$, for women; HR: 1.605 , [95\% CI: $0.952-2.704], \mathrm{p}=0.076$ for men) and current smoking (HR 2.486, [95\% CI: 0.668-10.872], $\mathrm{p}=0.226$, for women; HR: 0.822 , [95\% CI: $0.532-1.271$ ], $\mathrm{p}=0.378$ for men) did not reach statistical significance.

According to the combined mortality-dependency at discharge, 831 patients had a mRS from 3 to 6 , and 847 had a mRS from 0 to 2 . The univariate analysis of factors related to combined mortality-dependency at discharge is summarized in Table 4. Predictors of combined mortality-dependency at discharge by Cox proportional hazards model are shown in Table 5. Arterial hypertension (HR 1.046 [95\% CI: 0.905$1.210] ; \mathrm{p}=0.543)$ and previous antiplatelet treatment (HR 0.931 [95\% CI: 0.779-1.114]; $\mathrm{p}=0.436$ ) did not reach statistical significance in the multivariante analysis. In addition, gender (HR 1.097 [95\% CI: $0.930-1.293] ; p=0.273$ ), did not reach statistical significance, so data were not stratified and analyzed by gender.

\section{Discussion}

Our study found that, in a prospective population with IS assessed in two centres, stroke severity at admission, ischemic heart disease, male gender, older age, and AF were independent predictors for in-hospital death. Stroke severity at admission measured by the NIHSS was the most powerful predictor of early
Table 2 Cox proportional hazards model. Independent predictors for in-hospital mortality

\begin{tabular}{llll}
\hline & HR & $95 \% \mathrm{Cl}$ & $\mathrm{p}$ \\
\hline NIHSS & 1.178 & $1.149-1.207$ & 0.0001 \\
Age & 1.044 & $1.026-1.061$ & 0.0001 \\
$\mathrm{AF}$ & 1.416 & $1.048-1.913$ & 0.023 \\
Male gender & 1.853 & $1.323-2.192$ & 0.0001 \\
Ischemic heart disease & 1.527 & $1.063-2.192$ & 0.022 \\
\hline
\end{tabular}

mortality $[1,14,25,36]$, with a HR of 1.178 [95\% CI: 1.149-1.207] for each further NIHSS point at admission. Additionally, the HR of early death for patients with past ischemic heart disease increased to 1.527 [95\% CI: 1.063-2.192]. The deleterious impact of previous ischemic heart disease in the early mortality after stroke has not been previously described.

Male gender, with a HR of 1.853 [95\% CI: $1.323-$ 2.192], was also an independent predictor of early death. This result contrasted in our series with the percentage of women who died during the hospitalization period, which was slightly higher than for men. This fact lead us to analyze the distribution of deaths according to age ( $<$ or $\geq 75$ years) and we found that, although in the whole series the mortality was higher in women, the percentage of men who died was higher in the group of $<75$ years as well as in the group of $\geq 75$ years (see Results section). Interestingly, $67 \%$ of men's mortality occurs in patients $\geq 75$ years whereas, in women, $83.3 \%$ of mortality occurs in this age group. This finding has been previously described as a higher age-specific rate of stroke death in women [6], and can explain the higher crude mortality rate in women. Most studies that have analyzed the differences in stroke morbidity/mortality in both genders have usually found a higher mortality or disability rate in women $[1,4,6,12,18,19,28,39]$, 
Table 3 Cox proportional hazards model. Independent predictors for in-hospital mortality according to gender

\begin{tabular}{|c|c|c|c|c|c|c|}
\hline & \multicolumn{3}{|c|}{ Women $(n=826)$} & \multicolumn{3}{|c|}{ Men $(n=852)$} \\
\hline & $H R$ & $95 \% \mathrm{Cl}$ & $p$ & $H R$ & $95 \% \mathrm{Cl}$ & $\mathrm{p}$ \\
\hline NIHSS & 1.225 & $1.169-1.283$ & 0.0001 & 1.165 & $1.129-1.202$ & 0.0001 \\
\hline $\mathrm{AF}$ & 2.183 & $1.403-3.396$ & 0.001 & 0.904 & $0.579-1.411$ & 0.656 \\
\hline Age & 1.040 & $1.015-1.067$ & 0.002 & 1.053 & $1.029-1.078$ & 0.0001 \\
\hline
\end{tabular}

Table 4 Univariate analysis of patients according to combined mortality disability at discharge after first ever ischemic stroke

\begin{tabular}{|c|c|c|c|c|}
\hline & $\begin{array}{l}\text { Total cases } \\
(n=1678)\end{array}$ & $\begin{array}{l}\mathrm{mRS} 3 \text { to } 6 \text { at discharge } \\
(\mathrm{n}=831)\end{array}$ & $\begin{array}{l}\mathrm{mRS} 0 \text { to } 2 \text { at discharge } \\
(\mathrm{n}=847)\end{array}$ & $\mathrm{P}$ value $(\mathrm{OR} 95 \% \mathrm{Cl})$ \\
\hline Mean age (SD), years & $72.8(12.3)$ & $74.4(11.2)$ & $69.3(12.3)$ & $0.0001(*)$ \\
\hline Men (\%) & $852(50.8)$ & $356(41.8)$ & $496(58.2)$ & \\
\hline Women (\%) & $826(49.8)$ & $475(57.5)$ & $351(42.5)$ & $0.0001\left(^{*}\right) 0.530(0.430-0.650)$ \\
\hline Arterial hypertension (\%) & $1022(60.9)$ & $534(64.3)$ & $488(57.6)$ & $0.005\left(^{*}\right) 1.323(1.086-1.610)$ \\
\hline Diabetes mellitus (\%) & $500(29.8)$ & $254(30.6)$ & $246(29.0)$ & $0.4961 .075(0.872-1.326)$ \\
\hline Ischemic heart disease (\%) & $247(14.7)$ & $133(16.0)$ & $114(13.5)$ & $0.141\left(^{*}\right) 1.225(0.935-1.606)$ \\
\hline Atrial fibrillation (\%) & $523(31.2)$ & $317(38.1)$ & $206(24.3)$ & $\left.0.0001{ }^{*}\right) 1.919(1.555-2.368)$ \\
\hline Current smoking (\%) & $467(27.8)$ & $172(20.7)$ & $295(34.8)$ & $0.0001(*) 0.492(0.395-0.613)$ \\
\hline Previous antiplatelet treatment (\%) & $335(20.0)$ & $180(21.7)$ & $155(18.3)$ & $0.085\left(^{*}\right) 1.234(0.971-1.569)$ \\
\hline Previous anticoagulant treatment (\%) & $77(4.6)$ & $43(5.2)$ & $34(4.0)$ & $0.2561 .305(0.823-2.968)$ \\
\hline NIHSS at admission, (median, q1-q3) & $7(3,16)$ & $13(8,18)$ & $3(2,6)$ & $0.0001\left(^{*}\right)$ \\
\hline
\end{tabular}

Mean values; SD values in parentheses

Median values; Quartile 1-3: quartile values in parentheses

${ }^{*}$ V Variables included in the Cox proportional hazards model

Table 5 Cox proportional hazards model. Independent predictors for combined mortality-disability at discharge in patients after first-ever ischemic stroke

\begin{tabular}{llll}
\hline & HR & $95 \% \mathrm{Cl}$ & $\mathrm{p}$ \\
\hline NIHSS & 1.052 & $1.041-1.063$ & 0.0001 \\
Age & 1.011 & $1.004-1.018$ & 0.002 \\
AF & 1.197 & $1.031-1.390$ & 0.019 \\
Smoking & 1.262 & $1.033-1.541$ & 0.023 \\
Ischemic heart disease & 1.222 & $1.004-1.488$ & 0.045 \\
\hline
\end{tabular}

probably due to an analysis based on the crude mortality ratios observed in both genders.

In our study, an older age was another independent poor predictor factor, a fact supported by previous reports $[3,9,18,22,31,32]$. Interestingly, a recent study [23] showed that mortality in older patients was higher when AF was present (HR: 1.39 for 30-day mortality). In the same way, we found that $\mathrm{AF}$ played an important role for stroke outcome since the presence of AF implied a HR of in-hospital death of 1.416 [95\% CI: 1.048-1.913]. The higher risk of early death observed in acute IS patients with $\operatorname{AF}[19,20$, 30] and the deleterious impact of AF on stroke outcome has been extensively reported $[8,18,22,26,33$, 38]. The gender-specific effect of AF on the risk of stroke and cardiovascular death was analyzed in the Copenhagen City Heart Study [15] during a follow-up of 5 years. After adjustment for age and co-morbidity, the effect of AF on the risk of stroke was 4.6-fold greater in women than in men, and the independent effect of AF on cardiovascular mortality rate was 2.5 -fold greater in women than in men, suggesting that $\mathrm{AF}$ is a much more pronounced risk factor for stroke and cardiovascular death in women than in men. The German Stroke Registers Study Group [18] has recently reported substantial differences on the impact of comorbid conditions on early outcome for men and women. In women, a higher age, the severity of stroke defined by the number of neurological deficits, and AF (HR: 1.3; [95\% CI: 1.0-1.6]) were independent predictors for in-hospital death. Meanwhile, in men, diabetes and previous stroke had a significant negative impact on early outcome in addition to the factors identified for women. Our results (Table 3 ) supports the notion that gender differences exist during the acute stroke phase. Whereas the impact of NIHSS, and age was similar in both gender, we found a clear difference on the impact of AF for women and men. After adjustment for confounders factors, AF was an independent predictor of early death just for women, with a HR of 2.183 [95\% CI: 1.403-3.396], whereas in men, AF has not impact on early mortality. 
There is no clear explanation for the specific deleterious role of $\mathrm{AF}$ for women, but there are some evidences suggesting that AF has a greater impact on women gender. A recent study has demonstrated that female sex is an independent risk factor for thromboembolic complications in patients with AF [13]. Interestingly, $\mathrm{AF}$ is associated with higher levels of prothrombotic status and endothelial dysfunction, but sex-related differences in these factors have not been demonstrated [13].

The combined analysis of mortality-dependency at hospital discharge, showed similar predictors to those observed for in-hospital mortality analysis: NIHSS (HR 1.05 [95\% CI: 1.041-1.063]), age (HR 1.011 [95\% CI: 1.004-1.018]), AF (HR 1.197 [95\% CI: 1.0311.390]), ischemic heart disease (HR 1.222 [95\% CI: 1.004-1.488]) and, interestingly, current smoking (HR 1.262 [95\% CI: 1.033-1.541]). A recent study has demonstrated that smoking increased the risk of mortality and morbidity among cardiovascular highrisk patients participating in the HOPE trial [11]. Gender had no impact on the combined mortalitydisability at discharge.

Some limitations of our study must be mentioned. We had no data about some interesting risk factors such are obesity and congestive heart failure. In addition, we excluded patients treated with t-PA and those included in neuroprotective clinical trials in order to get a more homogeneous series. We believe that exclusion of such patients is justified because patients treated in neuroprotective trials were included in mRECT or in SAINT-I studies, and both trials showed a possible effect- negative for mRECT and positive for SAINT-I- on clinical outcome. Finally, patients were prospectively studied in two different University Hospitals, but no differences were detected in mortality between the centres after adjustment for gender, age, AF, ischemic heart disease and NIHSS (HR 1.183 [95\% CI $0.755-1.853]$; $\mathrm{p}=0.463)$.

In conclusion, our study provides evidence suggesting that differences related to gender exist in the determinants of early death after IS. Adjusted for confounders, mortality is higher in men than in women although more women than men died during hospitalization, and AF is an independent poor predictor just for women. All these differences provide a more accurate tool to better predict in-hospital outcome in patients with first ever IS.

\section{References}

1. Adams HP Jr, Davis PH, Leira EC, Chang KC, Bendixen BH, Clarke WR, Woolson RF, Hansen MD (1999) Baseline NIH Stroke Scale score strongly predicts outcome after stroke: A report of the Trial of Org 10172 in Acute Stroke Treatment (TOAST). Neurology 53:126-31

2. Aho K, Harmsen P, Hatano S, Marquardsen J, Smirnov VE, Strasser T (1980) Cerebrovascular disease in the community: results of a WHO collaborative study. Bull World Health Org 58: 113130

3. Arboix A, Garcia-Eroles L, Massons J, Oliveres M, Targa C (2000) Acute stroke in very old people: clinical features and predictors of in-hospital mortality. J Am Geriatr Soc 48:36-41

4. Arboix A, Oliveres M, Garcia-Eroles L, Maragall C, Massons J, Targa C (2001) Acute cerebrovascular disease in women. Eur Neurol 45:199-205

5. Aslanyan S, Weir CJ, Lees KR (2004) GAIN International Steering Committee and Investigators. Elevated pulse pressure during the acute period of ischemic stroke is associated with poor stroke outcome. Stroke 35:153-5
6. Ayala C, Croft JB, Greenlund KJ, Keenan NL, Donehoo RS, Malarcher AM, Mensah GA (2002) Sex differences in US mortality rates for stroke and stroke subtypes by race/ethnicity and age, 1995-1998. Stroke 33:1197-201

7. Castillo J, Leira R, Garcia MM, Serena J, Blanco M, Dávalos A (2004) Blood pressure decrease during the acute phase of ischemic stroke is associated with brain injury and poor stroke outcome. Stroke 35:520-6

8. Censori B, Camerlingo $\mathrm{M}$, Casto $\mathrm{L}$, Ferraro B, Gazzaniga GC, Cesana B, Mamoli A (1993) Prognostic factors in first-ever stroke in the carotid artery territory seen within 6 hours after onset. Stroke 24:532-5

9. Collins TC, Petersen NJ, Menke TJ, Souchek J, Foster W, Ashton CM (2003) Short-term, intermediate-term, and long-term mortality in patients hospitalized for stroke. J Clin Epidemiol 56:81-7

10. Cucchiara BL, Kasner SE, Wolk DA, Lyden PD, Knappertz VA, Ashwood T, Odergren T, Nordlund A (2004) CLASS-I Investigators. Early impairment in consciousness predicts mortality after hemispheric ischemic stroke. Crit Care Med 32:241-5
11. Dagenais GR, Yi Q, Lonn E, Sleight P, Ostergren J, Yusuf S (2005) HOPE Trial Investigators. Impact of cigarette smoking in high-risk patients participating in a clinical trial. A substudy from the Heart Outcomes Prevention Evaluation (HOPE) trial. Eur J Cardiovasc Prev Rehabil 12:75-81

12. Di Carlo A, Lamassa M, Baldereschi M, Pracucci G, Basile AM, Wolfe CD, Giroud $M$, Rudd $A$, Ghetti $A$, Inzitari D (2003) European BIOMED Study of Stroke Care Group. Sex differences in the clinical presentation, resource use, and 3-month outcome of acute stroke in Europe: data from a multicenter multinational hospital-based registry. Stroke 34:1114-9

13. Fang MC, Singer DE, Chang $Y$, Hylek EM, Henault LE, Jensvold NG, Go AS (2005) Gender differences in the risk of ischemic stroke and peripheral embolism in atrial fibrillation: the AnTicoagulation and Risk factors In Atrial fibrillation (ATRIA) study. Circulation 112:1687-91 
14. Frankel MR, Morgenstern LB, Kwiatkowski T, Lu M, Tilley BC, Broderick JP, Libman R, Levine SR, Brott T (2000) Predicting prognosis after stroke: a placebo group analysis from the National Institute of Neurological Disorders and Stroke rt-PA Stroke Trial. Neurology 55:952-9

15. Friberg J, Scharling H, Gadsboll N, Truelsen T, Jensen GB (2004) Copenhagen City Heart Study.Comparison of the impact of atrial fibrillation on the risk of stroke and cardiovascular death in women versus men (The Copenhagen City Heart Study). Am J Cardiol 94:889-94

16. Goldstein LR, Bertels C, Davis JN (1989) Interrater reliability of the NIH Stroke Scale. Arch Neurol 46:660-662

17. Goldstein LR, Samsa GP (1997) Reliability of the National Institutes of Health Stroke Scale. Extension to nonneurologists in the context of a clinical trial. Stroke 28:307-310

18. Heuschmann PU, Kolominsky-Rabas PL, Misselwitz B, Hermanek P, Leffmann C, Janzen RW, Rother J, Buecker-Nott HJ, Berger K (2004) German Stroke Registers Study Group. Predictors of in-hospital mortality and attributable risks of death after ischemic stroke: the German Stroke Registers Study Group. Arch Intern Med 164:1761-8

19. Holroyd-Leduc JM, Kapral MK, Austin PC, Tu JV (2000) Sex differences and similarities in the management and outcome of stroke patients. Stroke 31:1833-7

20. Jorgensen HS, Nakayama H, Reith J, Raaschou HO, Olsen TS (1996) Acute stroke with atrial fibrillation. The Copenhagen Stroke Study. Stroke 27:1765-9

21. Kaarisalo MM, Immonen-Raiha $P$, Marttila RJ, Salomaa V, Kaarsalo E, Salmi K, Sarti C, Sivenius J, Torppa J, Tuomilehto J (1997) Atrial fibrillation and stroke. Mortality and causes of death after the first acute ischemic stroke. Stroke 28:311-5
22. Kammersgaard LP, Jorgensen HS, Reith J, Nakayama H, Pedersen PM, Olsen TS (2004) Copenhagen Stroke Study. Short- and long-term prognosis for very old stroke patients. The Copenhagen Stroke Study. Age Ageing 33:149-54

23. Marini C, Baldassarre M, Russo $T$, De Santis F, Sacco S, Ciancarelli I, Carolei A (2004) Burden of first-ever ischemic stroke in the oldest old: evidence from a population-based study. Neurology 62:77-81

24. Moulin T, Tatu L, Vuillier F, Berger E, Chavot D, Rumbach L (2000) Role of a stroke data bank in evaluating cerebral infarction subtypes: patterns and outcome of 1,776 consecutive patients from the Besançon stroke registry. Cerebrovasc Dis 10:261-71

25. Muir KW, Weir CJ, Murray GD, Povey C, Lees KR (1996) Comparison of neurological scales and scoring systems for acute stroke prognosis. Stroke 27:1817-1820

26. Palomeras Soler E, Roquer Gonzalez J (2000) Ictus y fibrilación auricular. Neurologia 15:51-7

27. Reith J, Jorgensen HS, Pedersen PM, Nakayama H, Raaschou HO, Jeppesen LL, Olsen TS (1996) Body temperature in acute stroke: relation to stroke severity, infarct size, mortality, and outcome. Lancet 347:422-5

28. Roquer J, Campello AR, Gomis M (2003) Sex differences in first-ever acute stroke. Stroke 34:1581-5

29. Sacco RL, Shi T, Zamanillo MC, Kargman DE (1994) Predictors of mortality and recurrence after hospitalized cerebral infarction in an urban community: the Northern Manhattan Stroke Study. Neurology 44:626-34

30. Saxena R, Lewis S, Berge E, Sandercock PA, Koudstaal PJ (2001) Risk of early death and recurrent stroke and effect of heparin in 3169 patients with acute ischemic stroke and atrial fibrillation in the International Stroke Trial. Stroke 32:2333-7
31. Sharma JC, Fletcher S, Vassallo $M$ (1999) Strokes in the elderly - higher acute and 3-month mortality - an explanation. Cerebrovasc Dis 9:2-9

32. Sheikh K, Brennan PJ, Meade TW, Smith DS, Goldenberg E (1983) Predictors of mortality and disability in stroke. J Epidemiol Community Health 37:70-74

33. Steger C, Pratter A, Martinek-Bregel M, Avanzini M, Valentin A, Slany J, Stollberger C (2004) Stroke patients with atrial fibrillation have a worse prognosis than patients without: data from the Austrian Stroke registry. Eur Heart J 25:1734-40

34. Vemmos KN, Tsivgoulis G, Spengos K, Zakopoulos N, Synetos A, Manios E, Konstantopoulou P, Mavrikakis M (2004) U-shaped relationship between mortality and admission blood pressure in patients with acute stroke. J Intern Med 255:257-65

35. Weimar C, Konig IR, Kraywinkel K, Ziegler A, Diener HC (2004) German Stroke Study Collaboration. Age and National Institutes of Health Stroke Scale Score within 6 hours after onset are accurate predictors of outcome after cerebral ischemia: development and external validation of prognostic models. Stroke 35:158-62

36. Weimar C, Ziegler A, Konig IR, Diener HC (2002) Predicting functional outcome and survival after acute ischemic stroke. J Neurol 249:888-95

37. Williams LS, Rotich J, Qi R, Fineberg N, Espay A, Bruno A, Fineberg SE, Tierney WR (2002) Effects of admission hyperglycemia on mortality and costs in acute ischemic stroke. Neurology 59:67-71

38. Wong KS (1999) Risk factors for early death in acute ischemic stroke and intracerebral hemorrhage: A prospective hospital-based study in Asia. Asian Acute Stroke Advisory Panel. Stroke 30:2326-30

39. Wyller TB, Sodring KM, Sveen U, Ljunggren AE, Bautz-Holter E (1997) Are there gender differences in functional outcome after stroke? Clin Rehabil 11:171-9 